\title{
Assistência social na realidade municipal: o SUAS e a prevalência do conservadorismo
}

\author{
Maísa Miralva da Silva \\ Pontifícia Universidade Católica de Goiás (PUC- Goiás)
}

Assistência social na realidade municipal: o SUAS e a prevalência do conservadorismo

Resumo: Este artigo pretende apresentar a concepção da política de assistência social que prevalece em três municípios goianos, os mais populosos, de economia mais desenvolvida e com maior produto interno bruto, entre 2011 e 2012. Foram analisados relatórios e planos de gestão, projetos e registros profissionais de cada unidade pública de atendimento da política nesses municípios, relativos aos anos de 2008 a 2012. Como principal resultado, registre-se que os avanços dos últimos anos nessa área, ainda não superaram o conservadorismo na sua compreensão e operacionalização.

Palavras-chave: Assistência social. SUAS. Município e conservadorismo.

Social Assistance in the Municipal Reality: the Single Social Assistance System and a Conservative Attitude towards Social Security

Abstract: This article presents the concept of the social assistance policy that prevails in three municipalities of Goiás State including the most populous, that with the most developed economy and that with the highest total economic production between 2011 and 2012. Reports and management plans, projects and professional records of each public service unit for social assistance policy in these municipalities were analyzed, for the years from 2008 - 2012. The main results found that the advances in recent years in this field still do not overcome conservative attitudes in their understanding and operationalization.

Keywords: Social Assistance. SUAS. Municipality and conservative. 


\section{Introdução}

A assistência social, a última das políticas a ser regulamentada desde seu reconhecimento no campo dos direitos da seguridade social, concebida na Constituição de 1988, é historicamente boicotada como direito da população e dever do Estado. Na área da saúde, luta-se para que esse direito não seja privatizado e as conquistas sigam avançando, na assistência social, no entanto, o desafio maior é que esta política se torne pública, sistemática, regulamentada e supere sua histórica condição de ação privada, seja pela filantropia ou pela benemerência ${ }^{1}$.

Uma definição importante dos anos 2000 para fortalecer a política de assistência social como direito e sua condição de pública, inscrita na esfera de obrigações do Estado e unificada no Brasil, é o Sistema Único de Assistência Social (SUAS), assegurado pela Lei n. 12.435/2011. Entretanto,

uma baliza que não podemos esquecer é a de que o Suas está sendo concebido e operacionalizado num contexto histórico adverso e muito diferenciado daquele que propiciou a formação do conceito de seguridade social da Constituição de 1988 e da LOAS em 1993 (BEHRING, 2011, p. 87).

Vale registrar que, desde os anos 1970, a crise capitalista vem provocando mudanças na relação de obrigatoriedade do Estado no tocante à política social. Nos anos 1990, a privatização e a focalização foram fomentadas, tanto pelo incentivo direto do Estado, quanto pela sua ausência na provisão de atendimento universal, com qualidade e direcionado para as necessidades e demandas da população. Como afirmam Braz e Netto (2007, p. 227), essas características marcam a entrada decisiva do ideário neoliberal no Brasil, ideologia que legitima o projeto do capital monopolista, no qual o Estado é demonizado e "apresentado como um trambolho anacrônico que deveria ser reformado". A reforma conduzida pelo grande capital é, na realidade, "um gigantesco processo de contrarreforma(s), destinado à supressão ou redução de direitos e garantias sociais". Nesse contexto, mantém-se a relação de atração e rejeição entre a assistência social e o trabalho (BOSCHETTI, 2003), pois ao mesmo tempo em que "o trabalho assalariado e protegido transforma-se em peça de museu" (SITCOVISKY, 2010, p.153), a assistência apresenta-se como mecanismo central de integração social, compensatória das contradições e desigualdades, sobretudo pela transferência condicionada de renda.

A despeito da hegemonia neoliberal e em decorrência de lutas e resistência dos trabalhadores, são inegáveis os avanços ocorridos na assistência social desde 1988 aos dias atuais. No entanto, a herança da histórica filantropização, do controle e moralização da questão social, voltados para a integração e a coesão societária, expõe as contradições da institucionalização do Sistema Único de Assistência Social como um processo novo. Ele se iniciou na perspectiva de superação das formas tradicionais de gestão dos serviços, programas, benefícios e projetos da assistência social, mas é constantemente interditado pelo conservadorismo renitente, pelos limites dos conceitos adotados, pelas condições em que se materializa e, ainda, pelo contexto neoliberal que confronta e derrui a lógica do direito. A direção neoliberal na política social brasileira, com a estratégia da contrarreforma, tensiona a proposta do sistema, interpondo o tecnicismo, com a seleção socioeconômica, valendo-se da focalização.

Não obstante, a condição federada e autônoma dos municípios, a complexidade dos problemas para os quais devem apresentar respostas, as suas particularidades (portes, capacidades de gestão), os distintos compromissos de cada mandato, os arranjos político-partidários e, com ele, a distribuição dos cargos, são condições que levam à heterogeneidade na implantação de uma política nacional, fazendo que não ocorra na mesma direção em todos os lugares. A principal razão dessa heterogeneidade é a concentração dos recursos públicos nos estados e União em detrimento do município, que acaba se subordinando aos outros níveis de governo, perdendo sua suposta autonomia pela quase completa dependência financeira em relação à apropriação do bolo orçamentário nacional. Assim, as gestões públicas municipais, ainda que de algum modo investidas de marcas e características ideológicas, político-partidárias, vão se arrastando na relação pragmática, constituída, sobretudo, pelo financiamento provindo da União.

$\mathrm{Na}$ área da assistência social, essa realidade é facilmente visualizada pelo crescimento dos orçamentos federais nos fundos municipais de assistência social, em detrimento de orçamento próprio. Quanto mais se amplia a transferência do primeiro, mais encolhe o segundo, o que não significa, porém, crescimento específico do orçamento federal para a área. Predominam a solidariedade familiar, comunitária e beneficente (parcerias) com novas nomenclaturas, mas com conteúdos que repetem o passado. Como sustenta Harvey (2010), os períodos de crise e de insegurança são propensos também ao reforço de valores afetos à família, à religião e ao Estado, para compensar as contradições. Ganham força a responsabilização familiar e as saídas subjetivas, individuais, focalizadas e compensatórias.

O SUAS nasceu no momento em que se aprofundavam ainda mais as amarras neoliberais, contexto em que o mote inicial, luta por direitos, é posto no mesmo patamar da noção de risco social. Segundo Iamamoto 
(2010), a noção de risco e de luta por direitos caracterizam um ecletismo na política social, pois os conceitos apresentados como complementares são opostos. Irmã da noção de risco é a vulnerabilidade social, ambas originárias do pensamento liberal e fundamentadas no modelo de proteção social disseminado pelo Banco Mundial desde os anos 2000. Conforme análise de Mota (2010, p. 21), "nessa direção está em andamento um novo movimento constitutivo da hegemonia das classes dominantes, desenvolvido com as armas da despolitização, em prol da conservação dos interesses daquela classe".

As regulamentações circunscritas ao SUAS, revelam-se sitiadas por essa lógica e submetidas à focalização, à contrarreforma e à ideologia dominante. Cada vez mais elas têm transformado a assistência social da condição de componente da seguridade social à de política subsidiária das ações minimalistas de enfrentamento da extrema pobreza, notadamente as monetarizadas e seu aparato burocrático e de controle social, para garantir o foco e o cumprimento de contrapartidas, isto é, na direção contrária das tímidas conquistas do legado constitucional. De acordo com Mota (2010, p. 145),

esse processo responde por uma aliança invisível entre a manutenção do anti-reformismo, a preservação da dinâmica capitalista e o atendimento das necessidades imediatas da população, sem que se projete qualquer iniciativa que reponha a centralidade do trabalho, o seu valor de uso social no horizonte do acesso aos meios de vida, ora transformados em necessidades geradoras da assistência social.

O imperativo "direito do cidadão e dever do Estado", maior conquista no campo jurídico da assistência social em mais de duas décadas, capitulou-se no contexto de crise e estratégias de seu enfrentamento pelo grande capital. Trata-se de estratégias que se espraiam por todos os rincões da vida, e na forma de compreendê-la, isto é, na visão de mundo, hegemonicamente mercadológica, privatista, individualista e de senso comum. Com raio de profusão amplo, essas estratégias fazem-se presentes nas orientações estabelecidas pelas políticas sociais e, sobretudo, na política de assistência social. É possível apreendê-las nas mudanças recentes condensadas na Política Nacional, na Norma Operacional Básica e em outras orientações normativas e resoluções subsequentes próprias ou a ela tangenciadas. Capitulada pelas estratégias de enfrentamento da crise e pelos princípios neoliberais (mais mercado, menos Estado, desregulação do trabalho etc.), os novos referentes, aparentemente um avanço, essencialmente seguem reproduzindo a (des)historização da pobreza (MOTA, 2010), nos seus termos e no seu enfrentamento, adotando, como núcleos estruturantes e fundamentais, a família e o território.

O SUAS, entretanto, foi criado para fortalecer a implantação unificada da política no território nacional, seu conjunto de direitos como obrigação do Estado, mas ainda não ultrapassou os limites de um avanço restrito a regulamentações e publicações, repletas de concepções que apresentam um novo jargão, mas não necessariamente uma nova proposta, cujo conteúdo ultrapasse os marcos do liberalismo. Logo, não tem sido ainda capaz de confrontar o renitente conservadorismo da assistência social e efetivá-la como direito.

Reunindo os elementos da concepção e direção com as condições de realização dessa política nos maiores municípios goianos, os achados da pesquisa revelam traços e tendências presentes e futuras dessa política social, características que não são únicas nem exclusivas, ainda que particularizadas.

\section{Metodologia}

Apreender a realidade da assistência social nos municípios pesquisados exigiu considerar que a divisão social da riqueza no mundo capitalista, por ser intensamente desigual, gera antagonismos e contradições tanto nas condições materiais de vida quanto nas concepções políticas, historicamente instituídas, as quais "representam, antes de tudo, as aspirações de determinados grupos ou classes de uma sociedade" (BASBAUM, 1978, p. 101). Desse modo, o sentido e o significado da assistência social, tanto os historicamente determinados na sociedade burguesa, quanto os atualmente expressos em referentes legalmente instituídos, requerem a crítica do conhecimento acumulado, a qual:

consiste em trazer ao exame racional, tornando-os conscientes, os seus fundamentos, os seus condicionamentos e os seus limites - ao mesmo tempo em que se faz a verificação dos conteúdos desse conhecimento a partir dos processos históricos reais (NETTO, 2009, p. 672).

Portanto, o contraponto passado e presente, parte e todo, ontologia e práxis é essencial quando se trata de compreender e explicar a historicidade da realidade social, pois a realidade é um objeto em movimento (IANNI, 1990). Trata-se de captar o momento atual sem perder o movimento do real. 
Por isso, o contexto de definição e implantação do SUAS requer uma reflexão que considere os avanços, mas também as contradições, as resistências, imprecisões e, sobretudo, a correspondência entre a direção nacional e a realidade municipal. É preciso estabelecer o confronto entre as novas denominações e as velhas intervenções, as quais reproduzem o histórico conservadorismo no campo da assistência social, o que exige considerar a falsa dicotomia entre teoria e prática, pois, conforme Kosik (1986, p. 11), o mundo real é oculto, apesar de nele se manifestar:

o complexo dos fenômenos que povoam o ambiente cotidiano e a atmosfera comum da vida humana, que, com sua regularidade, imediatismo e evidência, penetram na consciência dos indivíduos agentes, assumindo um aspecto independente e natural, constitui o mundo da pseudoconcreticidade.

Assim, o que se busca demonstrar na análise é a essência que se manifesta no fenômeno, mas que apreende da historicidade a concepção vigente, tanto na direção nacional quanto na realidade municipal, em que se materializa o acesso (ou não) aos direitos por meio da política de assistência social.

A análise é fruto da pesquisa sobre a realidade da assistência social de três municípios de grande porte, os mais populosos, de economia mais desenvolvida e com maior produto interno bruto do estado de Goiás: Goiânia (capital/metrópole), Anápolis e Aparecida de Goiânia. Para apreender de que maneira a concepção de assistência social vigente vem sendo materializada na dinâmica dos municípios, isto é, as nuanças desse processo histórico-social, foram realizadas pesquisa bibliográfica, documental e de campo por meio de visitas aos equipamentos públicos municipais, com a finalidade de levantar dados relativos à operacionalização dos serviços, programas, benefícios e projetos na rede básica e especial do SUAS. Foram realizadas observações do cotidiano de trabalho, das estruturas de atendimento e da dinâmica de relação com os usuários. As fontes de acesso aos dados foram os planos plurianuais municipais de assistência, os relatórios anuais de gestão, os relatórios mensais das unidades denominadas Centros de Referência de Assistência Social (CRAS) e Centros de Referência Especializados de Assistência Social (CREAS), relativos aos programas, projetos e planos, bem como a realização de reuniões com equipes profissionais nas unidades de assistência social, em cada um dos três municípios. Em Aparecida de Goiânia todas as unidades foram visitadas, no total de cinco, algumas mais de uma vez. Em Anápolis foram visitadas todas as unidades dos dois níveis de atendimento, no total de seis. Já, em Goiânia, detentora de um número bem maior de unidades, foram visitados seis CRAS, localizados em distintas regiões da cidade, e metade do número de CREAS, dos quatro, então, existentes. Adotou-se como critério de escolha a antiguidade de funcionamento e distintas localizações na capital.

\section{Resultados}

Constatou-se que, mesmo no contexto da hegemonia neoliberal, ocorreram avanços, mas a herança histórica do conservadorismo expõe as contradições da institucionalização do Sistema Único de Assistência Social. Há uma distância entre o que está estabelecido nos referentes legais e nas normativas subsequentes com o que se realiza na esfera municipal. Além disso, a concepção nacional vigente tem sido indutora de um novo jargão, mas limitado à mesma e velha prática. Nas realidades municipais estudadas, prevalecem o tecnicismo, a fragmentação, o assistencialismo, com desprofissionalização e voluntarismo. São traços comuns as tendências à psicologização, à moralização e ao controle social dos usuários, à ausência de compreensão da assistência social, às condições precárias de trabalho, recursos insuficientes e equipamentos inadequados para $\mathrm{o}$ atendimento com qualidade. Pautado, sobretudo, pelas demandas da transferência de renda condicionada, notadamente o Bolsa Família, o SUAS inova na aparência, mas essencialmente segue confirmando as características de um Estado liberal, tanto na concepção quanto na implementação, pois mantém a disjunção entre a política e a economia no enfrentamento focalizado das expressões da questão social.

Os traços e as tendências identificados na pesquisa, por meio dos elementos da realidade hodierna dos municípios investigados, serão expostos a seguir, elucidando o resultado do estudo da concepção que prevalece nessas localidades, com base na direção nacionalmente empreendida.

\section{Tendências e traços da realidade municipal do SUAS}

Há uma distância entre o que foi plasmado nas já limitadas conquistas constitucionais e a regulamentação subsequente, relativas à assistência social, tanto no aspecto teórico-normativo vigente como na atuação municipal. Vazia de conteúdo legal no campo do direito devido pelo Estado, com acesso a bens e serviços 
sistemáticos, objetivamente identificáveis, a assistência social apresenta predominantemente respostas desqualificadas, casuísticas e assistencialistas.

As terminologias presentes nas novas orientações, de inspiração liberal e pós-moderna, fortalecem a tendência já pré-existente nos municípios. A conjunção entre condições precárias de trabalho, recursos insuficientes para atendimento de direitos e pouca ou nenhuma compreensão da política constituem o terreno fértil para o crescimento das abordagens que se voltam para a dimensão subjetiva, tendendo a restringir o trabalho social e as respostas, necessariamente objetivas, em abordagem psicologista.

O moralismo é um traço forte no que concerne às abordagens relativas às várias expressões da questão social, alia-se ao princípio da subsidiariedade, concepção liberal historicamente adotada pela igreja, que compreende o papel do Estado como complementar e de apoio e não como principal responsável em garantir direitos e acesso universalizado.

A tríade de atividades predominantes nas unidades da chamada proteção social básica constituída por Programas de Transferência de Renda (PTRs), visitas domiciliares relativas ao controle de condicionalidade e inclusão produtiva, evidenciam a concepção de assistência social que fomenta garantia compensatória, temporária e minimalista, que combina solução precária e controle comportamental do seu público. Essa situação põe as visitas domiciliares no ranking das atividades mais realizadas atualmente por essa política, não só nos municípios relativos a essa pesquisa, mas no Brasil (BRASIL/MDS/IBGE, 2009), ainda que a demanda mais frequente dos usuários sejam as cestas básicas emergenciais, denunciando e comprovando o pífio alcance das garantias atuais. A transferência de renda - assistencialização monetarizada minimalista - destitui a assistência social de suas vicissitudes e possibilidades como política de seguridade social.

A tendência burocrático-tecnicista é real e crescente na realidade dos municípios, pois induzida pelo conteúdo que a política operacionaliza, no caso, na condição de "barriga de aluguel" (SPOSATI, 2004) dos Programas Bolsa Família (PBF), Brasil sem Miséria, Minha Casa, Minha Vida e outros. O que faz que se amplie ainda mais o controle social sobre a demanda e reduza a possibilidade de articulação intersetorial dos direitos. Os serviços sucumbem às premências da burocracia relativa à inserção e ao controle dos que buscam o benefício monetário ou outros programas imediatistas e compensatórios.

O autoritarismo é traço característico do trabalho social. As possíveis formas de organização coletiva dos usuários, de suas resistências, bem como suas realidades de classe e limites relativos às suas privações não são matérias sobre as quais se debruça a política de assistência social realizada. Predomina a ausência de incentivo à mobilização social, à organização dos usuários, à participação da população nas instâncias de controle democrático e, sobretudo, a ausência de reflexão crítica de sua realidade e conhecimento dos direitos relativos à política de assistência social. Nesse sentido, a possibilidade de controle social dos pobres é um deleite para a perspectiva autoritária: ambas trabalham juntas e são predominantes na ação dos poderes públicos municipais. No mesmo viés autoritário, a relação com os usuários é estabelecida, muitas vezes, com caráter clientelista e imediatista.

Por meio do PBF, há uma recentralização da relação entre os entes federados, que afeta o princípio da autonomia dos municípios. Essa questão, aliada à falta de recursos próprios para a assistência social, vem reeditando uma antiga relação entre governo federal e municípios, fazendo que eles sejam executores de programas daquele. Nesse bojo, há um aumento de contratos determinados por editais, em que o município entra com contrapartidas irrisórias para executar projetos definidos na União.

O patrimonialismo com o primeiro-damismo é traço característico marcante no trajeto histórico dessa política social e, pelo visto, longe de ser superado. Nos municípios, ainda que a primeira dama não seja a secretária, ela presta contas à sociedade no que se refere à área social, exercendo o seu "papel natural" de mulher (do prefeito) comprometida com os pobres. E, se é secretária, explicita a desprofissionalização, exerce o nepotismo e o patrimonialismo, fortalece o assistencialismo, o clientelismo, o amadorismo e outros ismos, cumprindo a tarefa de ajudar o marido no seu projeto de poder. Verificou-se que o primeiro-damismo é uma cultura e não só uma condição. Há aquelas que exercem o cargo, e, embora não sejam esposas de prefeito, praticam o mesmo método.

O trabalho social com famílias, ao buscar o objetivo do Serviço de Proteção e Atendimento Integral à Família (PAIF), de fortalecer vínculos, mediante padrões socialmente determinados e conservadores, reforça o familismo, com responsabilização das famílias por suas condições de pobreza, de fracasso na educação dos filhos e que elas são as possibilidades de mudança de suas condições, ao buscar o sucesso próprio e dos fillhos, com a ajuda do poder público. Nessa relação, as mulheres são identificadas como principais responsáveis pela tarefa.

É traço característico nas ações que a assistência social vem realizando, a busca de soluções subjetivas, psicológicas e individualizadas, que apostam na elevação da autoestima para alcançar o empoderamento, a autonomia, a felicidade e o bem-estar familiar e social. Essa direção, que já compõe o pensamento conservador predominante da sociedade brasileira, estabelecendo o espírito de enfrentamento da crise, é fomentada pelas 
orientações nacionais e que os municípios tomam como referência no trabalho social que realizam. Ainda que muito se tenha feito para clarificar o papel da assistência social, seus serviços essenciais e as aquisições que deve assegurar, o fato é que as práticas tidas como pretéritas são reafirmadas e perpetuadas nos municípios. Ainda impera a imprecisão conceitual e de objetivos dessa política, agora mais complexa nas suas finalidades, situação agravada pelo pouco domínio crítico, na sua formulação, execução e sistematização. Falta compreensão clara de seu papel, alcance e objetivos, com base na realidade da população e de suas necessidades.

Seguindo os referentes nacionais, o fortalecimento da autoestima é traço comum e fundamental do trabalho social realizado pelos municípios nos dois níveis de proteção social do SUAS. No entanto, a pesquisa comprovou que esse propósito se efetiva por meio de atividades ligeiras, superficiais, dentre as quais, psicoterapias individuais rápidas, trabalhos manuais tradicionais, terapias em grupo, orações, grupos tradicionais de convivência, dentre outros. Nessa direção psicologizante, tanto a demanda quanto o seu atendimento/solução são idealistas, põem-se do ponto de vista do sujeito e não dos processos históricos em que se insere e em que se constitui. Algumas dessas ações são próprias de outras áreas, nesse caso, a saúde. A assistência social, fugindo às suas competências, assume serviços próprios de outras áreas como saúde e educação. De fato, a ambiguidade das orientações nacionais induz os municípios a essa situação, pois ao mesmo tempo que faz o discurso contrário ao trabalho terapêutico, adota termos que lhe são próprios. O resultado é um serviço camuflado e sem qualidade, e o prejuízo é para quem os recebe.

\section{É preciso resgatar a luta por} direitos e por serviços de qualidade, planejados e com participação popular.

O estímulo ao consumismo e ao endividamento dos usuários, sobretudo das mulheres, com o chamado Dia da Beleza é outra tendência comum verificada. Com os motes da autoestima, do fetiche da beleza e da supervalorização da aparência física, essa ação, frequentemente realizada nos Centros de Referência da Assistência Social (CRAS) com o propósito declarado de autocuidado, faz propaganda de cosméticos e estimula o aquecimento do mercado e a alienação dessas pessoas. Essas práticas creditam a felicidade à aparência, reproduzem alienação e opressão, não cumprem o papel da política e são extremamente funcionais para o capital e seu principal objetivo: o lucro.

Verifica-se o crescimento dos recursos federais e a relação por edital, com perda de autonomia municipal. Assim, os municípios tendem a realizar somente o que é financiado pelo governo federal, negligenciando aquelas ações que são de sua responsabilidade e dormitam pela falta de recursos, a cada dia mais minguados. Os orçamentos próprios para a área são exíguos, e as execuções orçamentárias a eles não correspondem, revelando um importante traço na obstrução da política.

No contexto de crescimento vegetativo e de cortes orçamentários e financeiros, cresce o estímulo ao setor privado e ao voluntariado. No mesmo ritmo em que aumentam os benefícios monetários condicionados pela legitimação social, tanto do governo federal como dos estados e municipais, outras ações ficam estagnadas e/ou encolhem os serviços, programas e projetos no campo do direito à assistência social.

É traço característico da realidade da assistência social nos municípios a prevalência de estruturas alugadas, cedidas (pela rede filantrópica e religiosa) e adaptadas, muitas das quais insuficientes, precárias e inadequadas. A condição de ocupante ou de inquilina contribui para aprisionar a política de assistência social à lógica, historicamente predominante, de filantropia e benemerência, em vez de investir na capacidade própria de instituir estruturas públicas compatíveis com as exigências de realização que preconiza o SUAS.

A existência de trabalhadores sem a qualificação necessária, predominantemente com contratos temporários precários, salários baixos, com constante atraso no pagamento, é traço comum na realidade da assistência social dos municípios. Compõe essa realidade o apadrinhamento e rotatividade da equipe, bem como a descontinuidade das ações, do vínculo com a realidade dos usuários, da proposta iniciada etc. A relação de favor estabelecida no contrato apadrinhado afeta a autonomia do profissional, do coordenador e das possibilidades de trabalho crítico. As equipes são sempre em número reduzido e insuficiente para o crescente trabalho técnico-burocrático, que consome tempo considerável dos trabalhadores. Apesar da realidade de precárias condições de trabalho, número insuficiente e rotatividade, o concurso público não é realizado na assistência social. A situação de trabalho desprotegido e mal remunerado não raro nivela os trabalhadores com as mesmas condições em que se encontram os demandatários de seus serviços no campo dessa política pública.

A ausência de condições, desde as mais básicas, para realizar atendimentos nos CRAS mobilizam os profissionais a práticas do tipo bazar de roupas usadas, para levantar recursos financeiros e fazer a manutenção mínima das atividades. Essa situação reproduz a benevolência, a caridade e o voluntarismo no âmbito dessa política, além de expor suas fragilidades e perpetuar a visão distorcida que a população, os trabalhadores e os 
usuários já têm sobre ela. Outro dado revelador da situação de investimento insuficiente nessa política é a sua dependência de doações das empresas, captadas pelo Programa Banco de Alimentos, que destina sua arrecadação para o abastecimento diário das unidades de atendimento, em detrimento do seu objetivo de origem.

A qualificação profissional e/ou inclusão produtiva é característica histórica e aposta renovada na realidade dos municípios, ação que não qualifica, não inclui no mundo do trabalho e não garante sobrevivência, mas segue como engodo da política. O que se realiza atualmente estimula a informalidade, a submissão a qualquer tipo de trabalho e fortalece a subproletarização dos desempregados. O engodo expõe-se na promessa do famigerado e tão apregoado binômio: autonomia e empoderamento. A expectativa da autonomia e do empoderamento não raro se materializa nas repetidas e conhecidas práticas de bordados, crochês, fuxicos, panos de prato etc. Essa tendência é reforçada pelas normativas vigentes e recém-confirmada em instrumento próprio referente à relação da política com o mundo do trabalho: a Resolução CNAS n. 33, que define como conteúdo da assistência social "o resgate da autoestima, autonomia e resiliência” (CNAS, 2011, p. 2).

É comum a continuidade do Programa de Erradicação do Trabalho Infantil (PETI) como jornada ampliada em vez de serviço de convivência e fortalecimento de vínculos, tal como preconizam os referentes atuais. Mesmo inserido no SUAS, esse programa não passa de atividades educacionais complementares, direcionado para um público focalizado, reproduzindo prática discriminatória e estigmatizadora, que o caracteriza como uma educação precária, sem qualidade, terceirizado, filantropizada, capturada por disciplinas militares e doutrinas religiosas. Trata-se de uma pobre política de complementação da educação formal, que substitui a lacuna da educação em tempo integral, ainda não universalizada.

Nos Benefícios Eventuais (BEs), campo de obrigação da política de assistência social, a concepção que impera nos municípios se revela plenamente. Percebe-se uma política distante dos seus enunciados iniciais, incompreendida, esvaziada de compromissos e postergada no cumprimento do seu papel, o de garantir acesso a direitos fundamentais. Há uma enorme distância entre o que se deva fazer e o que se tem logrado realizar. No campo das necessidades elementares, faltam condições adequadas nos municípios para atender a população em suas demandas, situação que leva os profissionais a recorrerem à benevolência para atendimento das necessidades mais prementes. O direito aos benefícios eventuais fica perdido, esquecido e continua negligenciado, sem regulamentação e sem pagamento.

Traço comum nas realidades pesquisadas é a instituição de um novo Benefício Eventual, o casamento comunitário. Com efeito, de proteção social, a assistência passa à proteção da propriedade privada, do espólio. Além disso, esses eventos tornaram-se importantes trunfos eleitoreiros dos governos de plantão no mais escancarado conservadorismo e fisiologismo, confirmando a tendência de reforço a essas instituições e valores em tempos de crise e suas estratégias de enfrentamento do capital. Esse benefício, além de não constituir um direito no âmbito dos objetivos legais, facilita o controle social sobre o comportamento dos pobres, na perspectiva da disciplina sexual, além de facilitar a gestão dos conflitos relativos à propriedade das casas de programas habitacionais populares, e, ainda, ampliar o horizonte já tão extenso da perspectiva familista, no caso, da família tradicional. O mais próprio dos BEs, auxílio funeral e natalidade, a rigor, não existe nos municípios. Prevalecem as práticas casuísticas, desprofissionalizadas, oportunistas, sem planejamento e sem atender a real demanda dos usuários.

Predomina, como tendência comum identificada na realidade dos municípios, a judicialização dos serviços da média complexidade, que se expressa com duas características: a impossibilidade de viabilizar direitos e recorrência ao judiciário para fazê-lo, sobretudo ao Ministério Público. Ainda, prevalece a submissão desse nível de complexidade a outros sistemas, notadamente do campo jurídico e de direitos do segmento da criança e adolescente, fazendo que as equipes dos CREAS sejam subordinadas à lógica do judiciário e não ao SUAS e à sua hierarquização.

A fragmentação das ações e a desarticulação interdisciplinar são também características comuns nas realidades estudadas. Prevalece a abordagem individualizada e por segmentos em detrimento da lógica de classe e frações de classe. Pode-se dizer que não existe a prática de planejamento coletivo, ao contrário, é comum que as equipes de trabalho se oponham. De um lado, os psicólogos ocupam as lacunas de outras políticas, notadamente a saúde, e os assistentes sociais confinam-se ao tecnicismo vigilante das condições de acesso para garantir a focalização determinada pelos diversos atendimentos.

Outro traço identificado é a latente capacidade de profusão das novas categorias para definição do público e das ações da assistência social: excluídos, risco e vulnerabilidade social, inclusão produtiva, resiliência, território, matricialidade sociofamiliar, autoestima e outras, ainda não generalizadas, mas já bastante apropriadas e repetidas na atuação dos municípios, tanto nos seus documentos quanto no trabalho corriqueiramente realizado. Essas categorias, "embora tenham capilaridade para explicar as manifestações singulares do real, revertem as possibilidades de análise crítica da sociedade e das determinações da desigualdade" (MOTA, 2012, p. 183). 
Na realidade, essas categorias expressam ideias fundamentadas nas concepções pós-modernas que rompem com as explicações amplas, interligadas e relacionadas à existência de classes sociais, passando a privilegiar os microespaços e as saídas de caráter subjetivo. Essa vertente não permite o discernimento das injustiças sociais e encerra o debate nos limites da ordem vigente, sem alcançar a perspectiva da democracia plena, fundamento da verdadeira autonomia. Ao eliminar as contradições, torna-se funcional à ordem do capital ${ }^{2}$.

Em virtude das tendências e características das realidades municipais, no que tange à política de assistência social, afirma-se que a dimensão do direito exige confrontar o voluntarismo, o moralismo, o assistencialismo, o patrimonialismo, o primeiro-damismo, o clientelismo e outros, bem como exige superar a fragmentação, o imediatismo, o acaso e a incerteza no atendimento à população. É preciso resgatar a luta por direitos e por serviços de qualidade, planejados e com participação popular. Essa direção tem o claro propósito de abalar a lógica do Estado burguês em favor dos interesses dos trabalhadores, democratizando o acesso à parte da riqueza socialmente produzida, por meio de investimentos oriundos do fundo público na política social, não como fim do túnel, mas como possibilidade de travessia.

Entretanto, o exercício de direitos é uma mediação anticapitalista, mas não chega a representar um projeto societário (MOTA, 2010). Por isso, a assistência social realizada historicamente, por todas as razões apresentadas, é política vazia de possibilidade de contribuir para o enfrentamento da pobreza e, menos ainda, da desigualdade e de seu processo de reprodução. A seguir nesse caminho, do conservadorismo, continuará sendo funcional à ordem do capital e à sua ideologia.

O SUAS representa uma possibilidade e seu presente e futuro seguem dependendo do montante de recursos e investimentos públicos que serão alocados, mas também da compreensão e, sobretudo, do compromisso de superar os vícios de uma assistência social conservadora e tradicionalista na abordagem às expressões da questão social. Essa prática histórica é reprodutora tanto das relações de favor e clientelistas, como das formas de apropriação privada da esfera pública.

Há pelo menos duas perspectivas (em disputa) no interior do SUAS: a que afirma a assistência social como política pública, direito da população e dever do Estado e a que reforça o legado conservador/tradicional da área, constituído, dentre outros aspectos, pela intervenção emergencial, improvisada e precária.

A educação continuada é uma importante estratégia para a formação de uma equipe qualificada e profissionalizada, mas a ela precedem a realização de concursos públicos, a definição de planos de carreira, salários dignos e condições adequadas de trabalho, assim como é necessário o investimento nos equipamentos públicos, nas estruturas de atendimento e nas condições do exercício de controle democrático pelos conselhos. Ainda, o SUAS só será realidade viva e crescente quando os seus usuários alcançarem a autonomia política necessária para a exigência coletiva e organizada de construção de outra realidade, de vida e social.

\section{Referências}

BASBAUM, L. Sociologia do materialismo: introdução á história da filosofia. São Paulo: Símbolo, 1978. BEHRING, E. R. Balanço crítico do SUAS e o trabalho do/a assistente social. In: SEMINÁRIO NACIONAL - O TRABALHO DO/ A ASSISTENTE SOCIAL NO SUAS. Anais... Brasília, 2011.

BOSCHETTI, I. Assistência Social no Brasil: um direito entre originalidade e Conservadorismo. Brasília: Ivanete Boschetti, 2003.

BRASIL. Congresso Nacional. Lei Ordinária n. 12.435, de 6 de julho de 2011. Altera a Lei n. 8.742 de 7/12/1993, que dispõe sobre a organização da Assistência Social e cria o SUAS. Disponível em: 〈http://www.mds.gov.br>. Acesso em: 6 ago. 2012.

BRASIL. IBGE. MDS. Relatório Pesquisa de Informações Básicas. Brasília, 2009. Disponível em: <http://www.mds.gov.br>. Acesso em: 4 mai. 2012.

CNAS - Resolução n. 33, de 28 de novembro de 2011. Define a promoção da integração ao mercado de trabalho no campo da assistência social e estabelece seus requisitos. Disponível em <http://www.mds.gov.br>. Acesso em: 3 jan. 2012.

HARVEY, D. Condição pós-moderna. São Paulo. Ed. Loyola, 2010.

IAMAMOTO, M. O novo ecletismo na política social brasileira: entre o "risco social" e a luta por direitos. In: ENCONTRO NACIONAL DE PESQUISADORES EM SERVIÇO SOCIAL (ENPESS) 12. Anais... 2010.

IANNI, O. A crise de paradigmas na sociologia. Revista Brasileira de Ciências Sociais. Ano 5, n. 13, jun., 1990.

KOSIK, K. Dialética do concreto. Tradução de Célia Neves e Alderico Toríbio. Rio de Janeiro, Paz e Terra: 1986.

MOTA, A. E. Redução da pobreza e aumento da desigualdade: um desafio teórico-político ao serviço social brasileiro. In: (Org.) MOTA,

A. E. As ideologias da contrarreforma e o serviço social. Recife, UFPE, 2010.

. AMARAL, A. S.; PERUZZO, J. F. O novo desenvolvimentismo e as políticas sociais na América Latina. In: MOTA, A. E.

(Org.) São Paulo: Cortez, 2012 (p. 153-178).

NETTO, J. P.; BRAZ, M. Economia Política: uma introdução crítica. São Paulo, Cortez: 2007. Biblioteca básica do Serviço Social. . Introdução ao método da teoria social. In: Serviço Social: direitos e competências profissionais. Brasília: CFESS, ABEPSS, 2009. 
SITCOVSKY, M. Particularidades da expansão da assistência social no Brasil. MOTA, A. E. (Org.). In: O mito da assistência social: ensaios sobre Estado, política e sociedade. São Paulo: Cortez, 2010.

SPOSATI, A. Especificidade e intersetorialidade da política de assistência social. Serviço Social \& Sociedade, n. 77, São Paulo: Cortez, $\operatorname{mar} / 2004$.

\section{Notas}

1 Os direitos da previdência continuam inacessíveis para quase metade da população que trabalha na informalidade. Para os outros trabalhadores, as perdas acumulam-se ao longo de várias reformas realizadas, que reduzem os direitos previdenciários no Brasil.

2 Essas expressões se baseiam nas orientações políticas de organismos internacionais como o Banco Mundial. São paradigmas liberais, da fase pósmoderna, que se caracterizam por suprimir as causas e os nexos das determinações econômicas da pobreza, buscando medidas para o ajustamento social, maquiando os efeitos mais perversos da lei geral de acumulação capitalista.

\section{Maísa Miralva da Silva}

maisa.silva@hotmail.com.br

Doutorado em Política Social pela Universidade de Brasília (UnB)

Professora do curso de Graduação e do Mestrado em Serviço Social na Pontifícia Universidade Católica de Goiás (PUC- Goiás)

\section{PUC- Goiás}

Av. Universitária, 1.440, Setor Universitário

Goiânia - Goiás - Brasil

CEP: 74.605-010 